
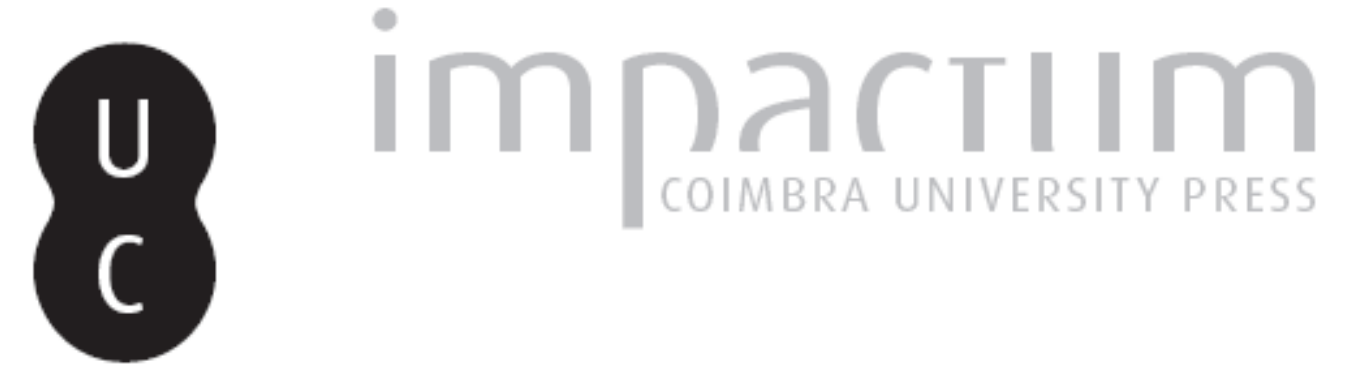

\title{
A experiência sensorial na comunicação turística
}

\section{Autor(es): Wichels, Susana}

Publicado por: Imprensa da Universidade de Coimbra

URL persistente:

URl:http://hdl.handle.net/10316.2/35518

DOI:

DOI:http://dx.doi.org/10.14195/0870-4112_11_20

Accessed : $\quad$ 26-Apr-2023 15:47:46

A navegação consulta e descarregamento dos títulos inseridos nas Bibliotecas Digitais UC Digitalis, UC Pombalina e UC Impactum, pressupõem a aceitação plena e sem reservas dos Termos e Condições de Uso destas Bibliotecas Digitais, disponíveis em https://digitalis.uc.pt/pt-pt/termos.

Conforme exposto nos referidos Termos e Condições de Uso, o descarregamento de títulos de acesso restrito requer uma licença válida de autorização devendo o utilizador aceder ao(s) documento(s) a partir de um endereço de IP da instituição detentora da supramencionada licença.

Ao utilizador é apenas permitido o descarregamento para uso pessoal, pelo que o emprego do(s) título(s) descarregado(s) para outro fim, designadamente comercial, carece de autorização do respetivo autor ou editor da obra.

Na medida em que todas as obras da UC Digitalis se encontram protegidas pelo Código do Direito de Autor e Direitos Conexos e demais legislação aplicável, toda a cópia, parcial ou total, deste documento, nos casos em que é legalmente admitida, deverá conter ou fazer-se acompanhar por este aviso.

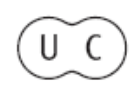




\section{ESTÉTICA E POLÍTICA}

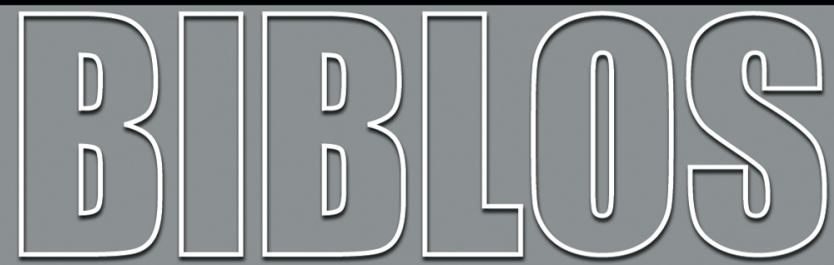

REVISTA DA FACULDADE DE LETRAS UNIVERSIDADE DE COIMBRA 
Biblos, n. s. XI (2013) 475-494

DOI: http://dx.doi.org/10.14195/0870-4112_11_20

SusANa WicheLS

Faculdade de Letras, Universidade de Coimbra

\section{A EXPERIÊNCIA SENSORIAL NA COMUNICAÇÃO TURÍSTICA}

\section{Resumo}

Entendendo o turismo como um fenómeno sociológico que corresponde à satisfação de necessidades de evasão, emoção, crescimento pessoal ou reconhecimento social, a comunicação turística deve definir estratégias assentes em modelos experienciais (Schmitt, 1999) e fornecer experiências que satisfaçam as necessidades e o desejo dos clientes. Os estudos em que baseamos este artigo (Gentile et al, 2007; Schmitt et al, 2013; Schmitt, Rogers e Vrotsos, 2003; entre outros) sugerem que a comunicação experiencial é a que tem demonstrado melhores resultados como fenómeno persuasor do consumidor e está por detrás da aura de produtos e serviços líderes de venda em mercados desenvolvidos.

O presente texto aborda um aspeto específico da comunicação turística, em concreto o modelo de comunicação e o marketing experiencial. Está estruturado em três partes: iniciamos com uma abordagem teórica relacionando o turismo e as experiências, posteriormente analisamos a comunicação e o marketing experiencial através da obra selecionada de Bernd Schmitt e finalmente, ilustramos com um estudo de caso de comunicação turística: a cadeia de hotéis-experiência, ME by Meliá, onde se aprecia a importância e o significado da experiência sensorial e dos sentimentos estéticos na comunicação com o cliente.

Palavras-chave: Experiências, Comunicação Experiencial, Marketing Experiencial, Experiências Turísticas, Bernd Schmitt

\footnotetext{
Abstract

To consume Tourism is to consume experiences (Scharpley, 2011). The tourism communication frequently makes use of images, texts and sound that represent sensorial experiences. It's inaccurate to think that Tourism sells only hotel beds or Holliday packages. Tourism sells dreams, offers experiences. It's therefore necessary to understand the way consumers experience places,
} 
cultures and people they visit. This article reviews the concept of communication based in the sensorial experience and the infl uence of experiences in the process of the consumer decision-making. We will also explore the concept of branding and experience based on the work of Bernd Schmitt, specifi cally the experiential strategic modules. The chosen methodology is the revision of literature, and we will conclude with an exploration of a hotel chain based in experiences, Me by Melia, that illustrates empirically the key concepts of experience marketing and communication revised in the article.

Key-Words: Experiences, Experiential Communication, Experiential Marketing, Tourism Experiences, Bernd Schmitt. 


\section{Sobre a Comunicação Turística}

O conceito do turismo evoluiu com os séculos e apresenta-se hoje como uma nova necessidade social de libertação, um meio de realização pessoal e de desenvolvimento da personalidade humana. As férias constituem o novo ideal sociológico porque ajudam o homem a superar o estado de alienação ocasionado pelo trabalho e pela vida social. $\mathrm{O}$ atual ritmo de vida provoca estados de ansiedade e a sociedade responde procurando atividades de fuga e fruição, longe da rotina diária e profissional. O processo de autoconhecimento do indivíduo passa hoje também por conhecer o mundo em que vivemos (Ponterio, 1991:22).

La capacidad organizativa hegemónica es la que predispone una serie icástica [natural, sin disfraz ni adorno] de descubrimientos emocionales que van desde el yoga hasta el karate, desde el esquí acuático hasta el surfing, desde el sentido de la libertad hasta el autocontrol, desde la arqueología hasta el folclore, a través de los cuales se realizan las valencias místicas de las que se nutre el turismo: ilusión, descanso, aislamiento, desapego, paz, serenidad, amor; valencias místicas que no renuevan un eterno aparecer de la felicidad sino una genuflexión, a ciegas, pagana verdadera adoración del hombre explotado que consagra a manera de fetiche al sincretismo de la población hábilmente ofrecido la porción de libertad que puede conducirlo de la nada al ser, del sufrimiento a la beatitud. (Ponterio, 1991: 13-14)

La nueva necesidad, las vacaciones, no es otra cosa que un momento de pausa, de ausencia en todas nuestras actividades, un periódico relajamiento insertado alternativamente en las individualidades biológicas, en las necesidades psíquicas y físicas de nuestra complejidad ontogénica. Constituye el requisito de todas las necesidades, desde la introducción del alimento en nuestro organismo hasta la exigencia de respeto, de salud del cuerpo, a través de todas las actividades culturales, intelectuales, míticas y religiosas. (Ponterio, 1991: 37-38)

"Fazer" turismo converteu-se, nos países desenvolvidos, na primeira atividade para satisfazer a necessidade de evasão. Ao aumentarem as possibilidades económicas e disponibilidade de tempo livre, a sociedade atual permitiu-se desenvolver uma vida satisfatória e cómoda, valorizando-se, todas aquelas experiências que oferecem 
diversão, segurança e entretenimento. John Urry em "Tourist Gaze" (1993) define ainda o turismo como um paradigma que resulta da divisão entre o ordinário e o quotidiano, por oposição ao anti-quotidiano, o extraordinário.

Neste contexto hedonista, Chamizo (2003) sugere que o indivíduo escolhe os produtos turísticos que oferecem o menor risco e sensações novas e memoráveis, já que procura uma experiência plena e satisfazer necessidades de realização e desenvolvimento pessoal.

A la hora de entender el importante papel que juega la imagen en la compra-venta de productos turísticos, es conveniente advertir que el consumo de éstos no viene a satisfacer en el individuo una necesidad básica, sino, más bien y según la pirámide de las necesidades de Maslow establecida en 1954, un deseo de realización y desarrollo personal. (Chamizo, 2003:93)

Os fornecedores de experiências turísticas, sejam eles destinos, países ou regiões, hotéis, parques temáticos, entidades públicas ou privadas utilizam vários instrumentos para comunicar-se de maneira formal e informal com os seus públicos externos e internos. O conceito de comunicação em turismo não se resume portanto, à promoção de um destino, engloba também os processos de sedução de um turista, as trocas culturais e rituais entre visitante e anfitrião, as narrativas turísticas sobre as quais se constroem as identidades das gentes, lugares e marcas. A comunicação turística é um meio promotor de ideias e ideais de proteção do património e do meio ambiente e está igualmente presente nas histórias e fragmentos de viagem contados pelos turista de regresso ao seu lugar de destino. Apresenta-se como um processo de representação e de construção de identidades socioculturais, pode ser encarada do ponto de vista semiótico, se analisarmos o discurso turístico, seja ele textual, pictórico, signos, símbolos, as intenções que o suportam e os diferentes significados descodificados por turistas, locais e outros atores turísticos.

Entendemos a comunicação em turismo como um processo complexo, omnipresente, bidireccional, simétrico e absolutamente necessário para criar, manter ou corrigir a imagem de um destino, empresa ou marca, fidelizar turistas, despertar o interesse, influenciar o processo de escolha e manter viva a recordação das experiências vividas de forma a provocar a recomendação e a volta. Como ressalta o texto de Marujo e 
Cravidão "A forma como a imagem de um lugar é veiculada pelos meios de comunicação pode ser fundamental para o processo de decisão do turista na visita a um país ou região" (Marujo e Cravidão, 2012: 282).

A comunicação turística pode ser entendida como um subsistema do sistema de comunicação, um processo de construção e disputa de sentidos no âmbito das relações turísticas (Baldissera, 2010) e que engloba as ações de relações públicas, propaganda e promoção de vendas de um destino (Doris Ruschman, 1991).

Os estudos sobre comunicação turística são ainda relativamente escassos e a sua produção iniciou-se timidamente no inicio na década de 90 com o trabalho dos turismólogos franceses, Marc Boyer e Philippe Viallon que correlacionaram pela primeira vez em "Communication Touristique" as áreas de conhecimento das ciências da comunicação com o turismo, entendendo-o já como fenómeno multifacetado e transdisciplinar. Mais tarde Baider et al (2004) reúnem em "La Communication Touristique, Approches discursives de l'identité et de l'altérité" uma das primeiras coleções de textos que propõem uma perspetiva discursiva, social e cultural. Aqui entende-se que o texto turístico, na ampla perspetiva de Paul Ricoeur (1986: 37) ou de Barthes (1996), ou as narrativas turísticas sejam elas narrativas verbais, textuais, pictóricas, contribuem para a experiência e a performance motivando ações, inações e desenvolvem relações sociais. Igualmente importante é a contribuição de Jacques Wainberg (2003) com "Turismo e Comunicação: a indústria da diferença" que propõe o turismo como um verdadeiro "fenómeno comunicacional" um ponto de encontro entre culturas, entre o visitante e o visitado, entre sociedades que se descobrem, um "fenómeno especial de comunicação humana" (Wainberg, 2003: 75). Uma das funções da comunicação é seduzir o turista, convidá-lo a lugares paradisíacos e a espaços contrários ao seu mundo quotidiano, oferecer-lhe experiências autênticas, narrar estórias de povos, lugares e culturas de forma a dotá-los de conteúdo digno de visita, ou nas palavras de Wainberg "apresentar o estranho como um produto não ameaçador e passivel de desfrute" (Wainberg, 2003: 75).

Não podemos deixar de referir que embora seja recente a abordagem da comunicação turística em ciências da comunicação, esta tem sido amplamente estudada dentro da área do marketing, talvez porque a função da comunicação está intrinsecamente ligada à captação e fidelização de turistas (ex: Tocquer e Zins, 1999; Shimp, 2002; Buhalis, 
2003; Kotler et al, 2008 entre outros). O marketing turístico é o processo pelo qual a estrutura da procura turística é antecipada e satisfeita através da conceção de um produto ou serviço, a distribuição física, a fixação de um valor de troca (Tocquer e Zins, 1999: 13), incluindo a comunicação entre a organização e os seus multistakeholders.

Uma das formas de posicionar-se nos mercados é estabelecer boas relações com os diferentes meios de comunicação, sejam eles tradicionais ou redes sociais. Os meios de comunicação têm uma grande influência junto do grande público e podem, em certos casos, prejudicar a imagem e a comunicação da organização turística (Tocquer e Zins, 1999: 21; Marujo e Cravidão, 2012). Mas se a comunicação com os meios de comunicação é bem gerida, estes apresentam-se como um dos meios mais eficazes para promover e construir a imagem de um destino. Os turistas são sensíveis à informação veiculada pelos meios de comunicação, e podem ser estimulados a desenvolver um interesse depois de terem sido expostos às representações mediáticas das experiências, lugares e culturas de um destino. As relações públicas devem favorecer e manter boas relações com os meios de comunicação social, já que têm a particularidade de tocar todos os grupos que constituem a esfera pública externa e interna.

A comunicação e o marketing turístico devem antecipar as mudanças nos desejos e necessidades dos consumidores e perceber que durante o processo de fidelização é importante tomar em consideração que os turistas desejam agora usufruir de novas experiências e com maior valor agregado. A fidelização dos turistas deve ser mais valorizada do que os esforços na captação de novos. Esta suposição está confirmada por evidências empíricas, no estudo apresentado por Reicheld e Sasser (1990: 105-111) onde concluem que é muito mais dispendioso atrair novos clientes que reter e fidelizar os já existentes. Middleton (1995: A1-08) refere-se a esta questão como o síndrome do leaky bucket, porque há destinos que ainda consideram que o primordial é encontrar novos turistas cada ano, independentemente do número que perdem devido à falta de atenção, qualidade no serviço ou má gestão comunicacional. Portanto, não só é necessário ativar novas campanhas em meios de comunicação para captar turistas, é igualmente aconselhável desenvolver ações que estimulem um relacionamento contínuo com os turistas que já visitaram o destino e que podem, eventualmente, transformar-se em prescriptores do mesmo. 
O conceito das experiências emerge na maioria das definições de produto turístico (Urry, 1993; Middleton, 1994; Cabarco Novás, 2006). É uma combinação de elementos tangíveis e experiências intangíveis, desenhada para satisfazer as necessidades ou o desejo do indivíduo, realizada num destino, percebida como uma experiência e disponível em troca de um preço (Middleton, 1994).

Los productos y servicios turísticos que hoy se ofertan en el mercado turístico deben ser presentados a sus potenciales consumidores con las mejores garantías de obtener un éxito no solamente comercial sino una satisfacción de las necesidades de los turistas demandantes de dichos productos y servicios. Para ello se impone una comunicación comercial lo más idónea posible que se puede conseguir a través de las modernas técnicas de marketing, de la publicidad y de las relaciones públicas. (MONTANER, 1991:267)

Entendemos que a aplicação da comunicação e do marketing ao turismo é talvez mais necessária que em outros setores, já que funciona como catalisador do processo de promoção, venda, distribuição e recomendação. Cabarco Novás (2006) postula que na esfera dos serviços turísticos tudo está relacionado com a comunicação e esta, por sua vez, tem como objetivo transmitir mensagens que influenciem a perceção dos públicos. Comunicar um produto turístico é comunicar uma promessa (Kotler et al, 2008;). Durante a fase da compra, o público destinatário percebe uma série de riscos derivado do caráter intangível do produto turístico. A impossibilidade de poder apreciar com os sentidos impede uma avaliação objetiva da qualidade do produto antes de adquiri-lo. O serviço não existe até ao instante do consumo e até esse momento o cliente não saberá se o que adquiriu corresponde à realidade esperada e à promessa comunicada (Kotler et al, 2008; Buhalis, 2003; Lumsdon, 1997).

Igualmente, a maioria dos produtos turísticos são pagos antes de serem desfrutados, o que aumenta o stress do cliente em relação ao cumprimento ou não das caraterísticas anunciadas. Para diminuir os riscos abrangidos na compra dos serviços turísticos e o gap entre expetativa e realidade, defendem Kotler et al (2008), que as estratégias de comunicação devem estar pensadas de forma a tornar tangível ao máximo o serviço, aproximando-o ao consumidor e acessível aos sentidos. Por isso um hotel deve facilitar peças de comunicação (folhetos, 
web, vídeos, apresentações) com textos e fotografias ilustrativas das diferentes áreas, dos restaurantes e dos pratos que aí se oferecem, mostrar pessoas relaxadas a desfrutar das piscinas e spas, crianças felizes no kidsclub e casais enamorados a celebrar com um copo de champanhe à luz do luar, entre outros estereótipos facilitadores da comunicação. Em suma, criar narrativas que transmitam não só as caraterísticas utilitárias, mas especialmente as promessas emocionais.

Torna-se portanto necessário, através da comunicação, materializar os serviços turísticos, através de folhetos, vídeos promocionais, tours virtuais, páginas web, stand em feiras com cenários paradisíacos, publirreportagens em meios de comunicação, em definitivo, em todos aqueles suportes e meios que permitam reduzir a intangibilidade, transmitir emoções e sugerir experiências.

\section{Comunicação e Marketing Experiencial}

Tendo estabelecida a importância da comunicação para o turismo e a relação do turismo com as experiências e as emoções, importa agora centrar-nos no tema nuclear deste artigo, a comunicação experiencial. Recorremos à obra de Bernd Schmitt, investigador e professor na Columbia Business University em Nova Iorque e um dos especialistas contemporâneos em marketing e comunicação experiencial. Tem uma vasta produção científica, da qual destacamos: Big think strategy: How to leverage bold ideas and leave small thinking behind (2007); Customer experience management: A revolutionary approach to connecting with your customers (2003); Experiential marketing: How to get customers to sense, feel, think, act and relate to your company and brands (1999); Marketing aesthetics: The strategic management of brands, identity and image (1997), entre outros.

Em “Experiencial Marketing” (1999) Bernd Schmitt sugere que a comunicação e o marketing experiencial se encontram em todo o lado, em várias indústrias e mercados (de consumo, serviços, tecnologia e industrial). São várias as organizações que utilizam a comunicação experiencial para desenvolver novos produtos, comunicar com os seus clientes, aumentar as relações comerciais, selecionar parceiros de negócio, desenhar ambientes de consumo offline e online. 
O conceito de experiência é entendido como o conjunto de perceções, sentimentos e pensamentos experienciados pelo consumidor quando exposto a marcas, produtos ou atividades de consumo, bem como as memórias dessas próprias experiências (Schmitt, 2010: 60).

(...) perceptions, feelings, and thoughts that consumers have when they encounter products and brands in the marketplace and engage in consumption activities - as well as the memory of such experiences. (Schmitt, 2010: 60)

No entanto, um dos primeiros trabalhos que relaciona o marketing e a comunicação com as experiências é o artigo de Holbrook e Hirschman (1982) "The Experiential Aspects of Consumption: Consumer Fantasies, Feelings, and Fun”. Os autores sugerem que a perspetiva experiencial tem um espírito fenomenológico e o consumo é um estado subjetivo da consciência. Em contraste com a perspetiva do processamento de informação, que ressalta a dimensão utilitária e funcional do produto ou serviço e estimula processos conscientes, a perspetiva experiencial proposta por Holbrook e Hirschman enfatiza o significado simbólico, estimula os processos subconscientes e trabalha com sinais não verbais. Na perspetiva experiencial do consumo, o afeto joga um papel importante, não só como estímulo de atitudes mas também de excitação emocional incluindo diversos estados emocionais (amor, ódio, desejo, ansiedade, felicidade, tédio, orgulho, dor, luxúria ou culpa).

Questiona-se assim as orientações tradicionais do marketing centradas no produto e nos seus componentes utilitários, apontando os benefícios do marketing e comunicação experienciais. Parece-nos adequada esta perspetiva já que nem sempre os indivíduos fazem escolhas racionais e muitas vezes são influenciados pelas emoções.

A comunicação experiencial engloba qualquer forma de atividade orientada ao cliente ou que com ele estabelece uma relação. As experiências podem ser evocadas por produtos, formas de embalagem, campanhas de comunicação, interações no ponto de venda, relações comerciais, eventos e outras atividades similares, offline ou online. Existem algumas posturas, no entanto, que entendem a comunicação e o marketing experiencial, ou as experiências de consumidores de forma mais circunscrita e aplicam o conceito apenas às interações, relações ou cer- 
tos eventos contextualizados. Por exemplo, LaSalle e Britton (2002: 30) entendem a comunicação experiencial como o conjunto das interações entre o consumidor e um produto ou a marca e que conduz a uma reação.

\section{$O$ valor experiencial}

O valor não reside só nos produtos e nos seus atributos, mas também na experiência, sentimentos e emoções oferecidas por esses objetos de consumo. Schmitt (2010) postula que os indivíduos esperam que um produto ou serviço tenha um valor utilitário que se efetiva durante o ato de consumo, sendo que o seu valor experiencial ou hedonístico, se cumpre durante o usufruto, e incluso antes e depois.

Levando esta linha de pensamento ao mundo hoteleiro, se o valor utilitário de uma estadia num hotel de cidade, é dormir confortavelmente numa cama limpa e assear-se num quarto de banho, o valor experiencial pode estar relacionado com o significado que tem para o indivíduo alojar-se nesse determinado hotel (prestígio, posição social). Pode residir numa experiência pré-consumo: o indivíduo alegra-se porque vai ficar alojado nesse hotel e poderá descansar, pois não terá que viajar essa noite. A natureza da experiência pode ser múltipla, já que se pode ter uma ou várias experiências durante a estadia: sentir-se confortável, mimado, seguro, desfrutar de bem-estar no spa ou de excelente gastronomia durante o jantar. $\mathrm{O}$ valor experiencial pode estender-se a experiências pós-consumo como por exemplo, a vontade de voltar, sentimentos positivos e consequente fidelização com a marca, ou estar presente na construção de narrativas de pós-experiência como o relatar de histórias e mostrar fotografias das instalações à família e amigos, entre outras.

Em "Experiental Marketing” e claramente influenciado pelo trabalho de John Dewey (1925), Schmitt propõe cinco tipos de perspetivas de marketing experiencial ou módulos estratégicos experienciais: -senseperceber; -feel- sentir; -think- pensar; -act- atuar; -relate- relacionar.

$\mathrm{O}$ "Sense Marketing" apela aos sentidos sensoriais dos consumidores (visão, audição, toque, paladar e olfato). O “Feel Marketing” apela às emoções e sentimentos interiores, variando desde uma leve sensação positiva em relação à marca (por exemplo a relação com uma marca de bolachas), até a emoções fortes e que produzem sensações de felicidade, 
orgulho e reconhecimento social (por exemplo, a relação de alguns consumidores com Harley Davidson ou Mercedes-Benz). O "Think Marketing" evoca o lado racional e envolve os consumidores em experiências cognitivas que desafiam o lado criativo e a capacidade de resolver problemas do consumidor. O "Act Marketing" estimula comportamentos físicos, estilos de vida e interações. Finalmente, o "Relate Marketing" desenvolve experiências que estimulam os desejos do consumidor em participar ou de pertencer a um determinado contexto social, de uma subcultura ou de uma comunidade.

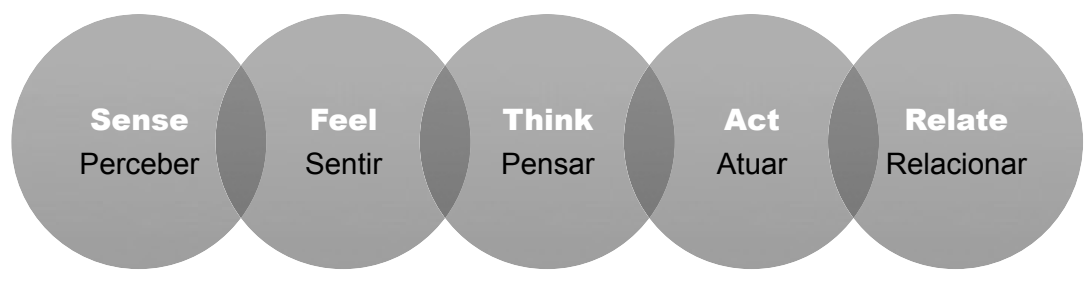

Ilustração 1 - Módulos estratégicos de marketing e comunicação experiencial de Bernd Schmitt. Elaboração Própria.

Numa entrevista concedida em 2000 à revista "HSM Management”, Bernd Schmitt explica esta sua abordagem:

Distingo cinco tipos de experiências, baseando-me em pesquisa de psicologia cognitiva, biologia evolutiva e marketing:

1. Se a questão for criar experiências para o cliente, perceber é uma experiência sensorial - por exemplo, oferecer algo bonito e excitante para os sentidos.

2. Sentir envolve estados de espírito, emoções e outros sentimentos.

3. Pensar significa criar um desafio intelectual interessante para o cliente, como a proposta de uma nova forma de consumo de um produto.

4. Agir está ligado a comportamentos e estilos de vida.

5. Relacionar-se tem a ver com experiências de relacionamento, tais como fazer o cliente sentir-se orgulhoso por estar consumindo um bom produto fabricado em seu país.

(Schmitt, HSM Management 23/ano 4/novembro - dezembro 2000) 
A perspetiva dos módulos estratégicos experienciais de Schmitt foi acolhida com êxito entre académicos e reinterpretada em alguns casos, como Gentile et al (2007), que acrescentam uma outra variante e entendem os módulos não como independente, mas sim que podem coexistir e inter-relacionar-se. Distinguem seis componentes experienciais: sensorial, emocional, cognitiva, pragmática, estilo de vida e relacional. Segundo esta abordagem, a dimensão sensorial inclui as experiências que estimulam sensações de prazer, excitação, satisfação ou o sentido de beleza/estética. A dimensão emocional abarca as experiências relacionadas com sentimentos, humores, emoções que criam uma relação afectiva com o produto/serviço, marca ou empresa. A dimensão cognitiva inclui as experiências relacionadas com os processos racionais e conscientes que estimulam a criatividade e a perspicácia do consumidor. A dimensão pragmática abrange as experiências relacionadas com o lado prático ou utilitário do produto. A dimensão estilo de vida compreende as experiências que afirmam valores e crenças pessoais. Já a dimensão relacional inclui as experiências que emergem de contextos sociais e que ocorrem durante o consumo coletivo ou inseridas numa comunidade real ou imaginária e que reforçam a identidade social do consumidor.

Depois da investigação de várias marcas, Gentile et al (2007) concluem que as experiências positivas são complexas e envolvem mais do que uma componente. Através de uma análise interpretativa, revelaram que certos produtos e marcas têm uma estratégia de comunicação e marketing que combina estes diferentes componentes e é precisamente dessa combinação que resulta a experiência singular e complexa, a aura do produto. Segundo os autores estas componentes experienciais não se ativam de forma independente, mas sim coexistem, inter-relacionam-se ou sobrepõem-se. Pensamos que este estudo de Gentile et al contribui com questões interessantes para a compreensão da natureza interativa, complexa e quase holística das experiências.

Verificamos que as marcas e produtos de êxito utilizam na sua estratégia de comunicação atributos experienciais, através de linguagem e imagens criativas e sedutoras e com caraterísticas experienciais: " $a$ plataforma comunicativa experiencial” proposta por Schmitt (2010: 89). Esta plataforma é multidimensional, multissensorial e altamente dinâmica. Ao pensar um serviço ou produto usando a plataforma experiencial, está-se a realizar um posicionamento experiencial que deve 
ser complementado com uma estratégia de comunicação e marketing experiencial e incluída num contexto sensorial offline e online.

Em "Functional and experiential routes to persuasion" (2013) Schmitt et al analisam 256 anúncios de televisão de 23 países para estudar a importância das técnicas de marketing de comunicação experiencial na persuasão dos consumidores. $\mathrm{O}$ estudo detetou um padrão de uso de dois modelos para a persuasão do consumidor: o funcional e o experiencial. O modelo funcional enfatiza as caraterísticas e os benefícios dos produtos e serviços, enquanto que o experiencial evoca sentimentos, sensações e a imaginação. Constataram também, que em mercados maduros e desenvolvidos (Europa e América do Norte), se utiliza de forma mais frequente o modelo experiencial, enquanto que em mercados emergentes ou em vias de desenvolvimento (Ásia, por exemplo), funciona melhor o modelo funcional como via de persuasão do consumidor. Talvez pelo desenvolvimento e maturação dos mercados de consumo europeus e norte-americano, verifica-se uma mudança na comunicação publicitária, que passou de funcional a experiencial (Schmitt, 1999; Schmitt, Rogers e Vrotsos, 2003). Uma possível explicação para esta mudança e recorrendo à teoria das motivações de Maslow (1954) reside no facto que em mercados desenvolvidos os consumidores têm a maioria das necessidades básicas asseguradas e estão portanto mais preocupados em satisfazer necessidades de mais alto valor (estética, reconhecimento social, orgulho e auto-expressão). Uma outra hipótese apresentada por Schmitt (2013) é que o modelo experiencial - com mensagens que estimulam as sensações - é o que melhor descreve o modelo de comunicação de persuasão publicitário em mercados desenvolvidos.

Por isso, embora a maioria dos produtos líderes de vendas, desde IPads aos Mini Cooper, apresentem um design inovador e a promessa de uma performance ótima, segundo Schmitt (2010: 56) esta dimensão utilitária não explica per se, o seu êxito de vendas, a identificação e a lealdade dos consumidores com a marca. O que estes produtos estrela têm em comum é a forma como são comunicados: mensagens que apelam às emoções, sentimentos, afetos, curiosidade e apresentam o produto como uma forma de expressão do consumidor, deixando em segundo plano, as caraterísticas utilitárias, racionais, cognitivas. Constatamos que este tipo de marketing e comunicação experiencial está a ser utilizado atualmente em várias indústrias e setores de consumo, 
desde companhias aéreas, comercio ao retalho, eletrónica, serviços financeiros, e em especial no setor turístico.

\section{Estudo de Caso: ME by Meliá}

Meliá Hotels International é um grupo hoteleiro espanhol que conta com mais de 350 hotéis em 35 países e cerca de 35.000 empregados. O portfólio de marcas está diferenciado, de forma a oferecer produtos turísticos a vários segmentos e tipologias de consumidores. Entre as marcas de luxo encontramos as "Gran Meliá", "Paradisus" e "ME by Meliá". Escolhemos "ME by Meliâ" como estudo de caso exemplificativo do uso de comunicação de experiências, porque surge como um conceito hoteleiro com caraterísticas diferenciadoras baseadas nas sensações. Encontramos este conceito não só na comunicação externa do produto, mas também nos serviços prestados e na comunicação interna, entendendo esta dimensão como abrangente da arquitetura, decoração e design pensado para produzir estímulos sensoriais. Descrevem-se como uma marca de hotéis com "personalidade, baseados no conceito de experiências e localizados tanto em destinos urbanos como em resorts em vários pontos do planeta" (Dossier de Imprensa de Me By Meliá: 2013).

A conceção do produto turístico é encarada como um todo holístico. Nos diferentes canais e peças de comunicação analisadas, tanto online como offline, diferenciam os seus produtos e serviços fornecendo experiências de consumo gratificantes e memoráveis aos consumidores. Tanto na sua web, folhetos ou vídeos promocionais, distanciam-se claramente da dimensão utilitária e centram-se quase exclusivamente na dimensão experiencial. Prometem ser "mais do que um lugar onde alojar-se é um lugar onde estar. Bem-vindo a uma experiência que vai muito mais além de uma simples estadia” (DI Me By Meliá: 2013).

Consideramos que esta marca apresenta uma visão de hotelaria experiencial, como evidencia esta passagem extraída da sua Web corporativa:

ME seduce la mentalidad abierta con arte, diseño, música y arte culinario. Una impresión, un momento, una sensación a la vez. Provocativo. Cautivador. ME extrae lo mejor de cada uno.

(retirado página Web ME: http://www.me-by-melia.com) 
Em todos os hotéis $M E$, a arquitetura exterior e interior aposta num desenho de vanguarda. Os serviços são concebidos para estimular os sentidos e oferecer experiências de consumo únicas: oferta gastronómica sibarita, a ultima tecnologia, aromaterapia, cromoterapia, música, entre outros. O serviço é construído sobre quatro atributos estratégicos: recorda, experimenta, energia e desafia e que relacionamos com os modelos estratégicos experienciais de Schmitt (1999):

RecuérdaME, ExperiméntaME, EnergízaME y DesafíaME, la perfecta combinación para crear la atmósfera que estimula los sentidos y conecta con el ritmo de vida de cada uno, con el AURA de cada cliente, que constituye la esencia del hotel. (Dossier de Imprensa de ME By Melia: 2013)

As diferentes peças de comunicação analisadas tanto online e offline, externas e internas, sugerem que os hotéis foram concebidos para indivíduos que procuram não só a qualidade, mas sim experiências individualizadas, vibrantes, num ambiente cosmopolita que seja reflexo das suas necessidades profissionais e desejos pessoais: "o ME é o hotel do indivíduo".

O módulo "sense marketing", que apela aos sentidos dos indivíduos (visão, audição, toque, paladar e olfato) é trabalhado especificamente por um departamento operativo, o "Aura Experience Departement" cuja função é criar estímulos, eventos e experiências nos hotéis, através de aromas, cores e sabores de forma a oferecer sensações de consumo memoráveis.

Verificamos que a estratégia de comunicação externa e interna de $M e$ se distancia dos aspetos funcionais e das referencias utilitárias, centrando-se nos aspetos experienciais através de conceitos verbais e imagéticos que ressaltam o valor sensorial e emocional do produto. As campanhas evocam intencionalmente sentimentos, emoções, sensações e estilos de vida, pretendendo estimular uma resposta afetiva por parte do consumidor.

Recentemente a marca lançou uma campanha intitulada "Bem-vindo ao Life-Management by Melia: a vida é a viagem mais importante”. As mensagens verbais e imagéticas traduzem os valores atributo da marca e aportam conselhos sobre a felicidade. O que Schmitt (2010) refere a nível teórico como sendo um dos objetivos do marketing e comunicação experiencial: o desenvolvimento não só de produtos e campa- 
nhas experienciais, mas também contribuir para a felicidade humana, está aqui a ser praticado a nível empírico. Um dos componentes desta campanha experiencial é a participação do psicólogo e escritor Mário Alonso Puig que realizou uma série de palestras e workshops sobre a gestão da felicidade nos hotéis da marca em todo o mundo. As palestras estão ainda disponíveis online, numa página criada especialmente para acolher a campanha (http://www.melia-hotels.com/life/\#/guru/). Todas as peças estão imbuídas de conceitos de inteligência emocional, felicidade para estimular experiências positivas e construtivas. Segundo dados fornecidos pela empresa, a campanha teve um excecional acolhimento por parte do público. A web monográfica "Life Management by Melia" teve 38.000 visitas nos primeiros dois meses, conseguiu duplicar os fans de Facebook da marca durante o pico da campanha, chegando aos 81.646 fans e a página de Facebook foi a segunda página hoteleira mais visitada em Espanha e a $20^{\mathrm{a}}$ a nível internacional nesse período. Este é outro exemplo de como $M E$ se posiciona experiencialmente. Ao relacionar-se com conceitos de bem-estar, espiritualidade, ativa a plataforma experiencial, passa a ser denominado como "energia para a vida" o que lhe confere um valor sensorial e emocional. Para além disso, estão ativar simultaneamente os módulos experienciais "Think, Act e Relate", já que evocam o lado racional, envolvendo os assistentes das palestras em experiências que desafiam o lado criativo e a capacidade de resolver problemas, estimula uma ação futura instruindo de como fazer um "Life management" e ainda criam uma rede social e espaço de debate de temas de inteligência emocional onde os clientes podem participar antes, durante e depois da estadia.

Analisando as imagens escolhidas por $M E$ para ilustrar os seus textos comunicacionais, verificamos o uso de modelos femininos e masculinos em poses sensuais. As roupas e as poses dos corpos comunicam um estilo de vida cosmopolita, vibrante e sensual. Sugere-se com esta escolha um estilo de hóspede, um estilo de vida. É uma linha de comunicação que se desprende da tradicional narrativa turística, onde normalmente encontramos representados os diferentes tipos de clientes possíveis, recorrendo aos estereótipos mais comuns e aceites pela sociedade: casais de tipo heterosexual, os jovens em lua de mel, os casais de meia idade, os casais seniores, as famílias grandes e com crianças, e o individuo sozinho a desfrutar de um momento de paz. Este tipo de comunicação costuma ser complementada com alguma referência ao 
país ou cultura anfitriã, normalmente através da escolha de uma fotografia onde o turista interage com um "local", ou ainda imagens que evidenciam caraterísticas raciais do outro, o "local" como diferente e portanto exótico ou típico. Nas campanhas de ME nenhum destes estereótipos foi utilizado, pelo contrário, existe uma comunicação centrada no valor emocional do produto, o hotel como destino, excluindo as referencias ao destino anfitrião. A única referencia visível e identificável é na denominação comercial que incluem, o "apelido do destino" (Borja et al, 2002: 43): "ME Cancún”, "ME Cabo", "ME Madrid”, "ME London", "ME Mallorca", "ME Ibiza" ou "ME Dubai". Através do uso da fórmula "ME + Cidade/Região", " $M E$ " corresponde aqui não só às primeiras letras de "Meliá", mas essencialmente a me, como pronome pessoal, cognato tanto em Inglês, Espanhol e Português, e cuja função é substituir o nome do indivíduo, sugerindo um apoderamento do destino. Em suma, pela escolha de experiências oferecidas e as representações, desde uma perspetiva crítica entendemos que " $M E$ " optou por uma estratégia de construção de destino turístico, onde se estimula o imaginário e as expetativas do turista, recorrendo aos módulos experienciais.

\section{Conclusão}

A comunicação é fundamental para o setor turístico, como facilitador do processo de distribuição e comercialização. Dada a natureza intangível do produto turístico a comunicação e o marketing têm como missão informar não só das caraterísticas utilitárias do produto, já intuídas pela maioria dos consumidores em mercados desenvolvidos, mas essencialmente das suas caraterísticas experienciais, despertando um interesse que estimule uma ação: reserva, compra ou consolidação do valor da marca. Contudo, embora a comunicação em turismo seja um processo fundamental são ainda poucos os estudos especializados em comunicação turística.

O turismo, fenómeno complexo e transdisciplinar, também é um fenómeno sociológico que corresponde à satisfação de necessidades de evasão, emoção, crescimento pessoal ou reconhecimento social na sociedade contemporânea. As atores turísticos, em especial os Gestores de Destino, Hotéis, Spas, Companhias Aéreas, entre outros, devem ter em conta esta caraterística e definir estratégias de comunicação assentes 
em modelos estratégicos experienciais de forma a satisfazer as necessidades de alta ordem e estimular o desejo no indivíduo. Através do exemplo da estratégia de comunicação de $M E$ by Meliá, podemos ver a aplicação empírica da plataforma experiencial proposta por Schmitt. Ao relacionarem os conceitos de bem-estar, espiritualidade e felicidade, e fazerem uso de conceitos verbais e imagéticos que ressaltam o valor sensorial, posicionam-se de forma emocional e experiencial. Encontrámos na estratégia de comunicação de $M E$ by Meliá, na representação, composição e variação estilística, um exemplo da conjugação dos diferentes módulos experienciais, uma proposta válida de como seduzir o turista, convidá-lo a lugares paradisíacos, a espaços contrários ao seu mundo quotidiano e oferecer-lhe experiências únicas. Sem embargo, não é uma campanha massificada, segmentam o mercado e dirigem-se aos gostos e desejos de indivíduos urbanos e com orientações cosmopolitas. Embora se apresentem como "ME é o hotel do indivíduo", são uma proposta hoteleira só para indivíduos com determinadas caraterísticas e que procuram uma experiência holística, centrada no gozo pessoal e destituída de vínculos com o país visitado. O conjunto de experiências hedonistas oferecidas por $M E$ não prioriza o encontro autêntico com o outro, ou com a cultura anfitriã e centra-se numa experiência pessoal, na fruição individual, no gozo próprio, deixando em segundo plano a realidade social onde se insere. A estratégia de comunicação de $M E$ by Meliá é um bom estudo caso de comunicação experiencial, no entanto levanta questões de outra índole, como a legitimidade de um tipo de turismo egocentrado onde existe pouco ou nenhum interesse pela cultura e país anfitrião, talvez uma reação da sociedade atual denominada por alguns como a era "selfie". Estes turistas egocentrados encontram aqui a possibilidade de relacionarem-se com os seus pares e olhar desde uma perspetiva cosmopolita os destinos que visitam, sejam eles Madrid, Londres ou Cabo.

\section{Bibliografia}

Rudimar Baldissera, Comunicação turística: a comunicação das Secretarias Municipais de Turismo da Rota Romântica, Vale dos Sinos e Paranhana. Revista Online Comunicação e Cultura, Vol. 9, No 17, 2010. 
Fabienne Baider, Marcel Burger e Dionysis Goutsos, La communication touristique: Approches discursives de l'identité et de l'altérité, Chipre, L' Harmattan, 2005.

Roland Barthes, O prazer do texto. 4. ${ }^{a}$ ed. Trad. J. Guinsburg. São Paulo, Elos, 1996.

Marc Boyer e Philippe Viallon, La communication touristique, Paris, PUF, 1994.

Dimitrios Buhalis, E-Tourism: Information technology for strategic tourism management, Harlow, Financial Times - Prentice Hall - Pearson Education, 2003.

Noélia Cabarcos Novás, Promoción y Venta de Servicios Turísticos: Comercialización de Servicios Turísticos, Vigo, Ideas Propias, 2006.

Rocío Chamizo SAnchéz, Introducción a la Comunicación Turística: El valor de la imagen en la comercialización de productos turísticos. Málaga, Textos Mínimos, Universidad de Málaga, 2003.

John Dewey, Experience and Nature. New York, NY: Dover, 1925.

Chiara Gentile, Nicola Spiller e Giuliano Noci, How to sustain the customer experience: An overview of experience components that co-create value with the customer, European Management ,Journal n. ${ }^{\circ} 25$, páginas 395$-410,2007$.

Morris B. Holbrook e Elizabeth C. Hirschman, The experiential aspects of consumption: Consumer fantasies, feelings, and fun. Journal of Consumer Research, n. ${ }^{\circ}$ 9, páginas 132-140, 1982.

Phillip Kotler, John Bowen e James C. Makens, Marketing para turismo, Madrid, Pearson Prentice Hall, 2008.

Jost KripPEndorf, The Holidaymakers, London, Heinemann, 1987.

Diana LaS alle e Thierry A. Britton, Priceless: Turning Ordinary Products into Extraordinary Experiences, Boston, Harvard Business School Press, 2002.

Les Lumsdon, Tourism Marketing, Oxford, International Thomson Business Press - Tourism and Hospitality Management Series, 1997.

NoÉmia Marujo e Fernanda CRAVIDÃo, Turismo e lugares uma perspectiva geográfica, Revista Passos, Vol. 10 N. ${ }^{\circ}$ 3, páginas 281-288, 2012.

Abraham Maslow, Motivation and Personality, Nova Yorque, Harper and Row, 1954.

Victor Middeton, Marketing in Travel and Tourism, Londers, Butterworth, 1994. 
Sergio Ponterio Vitale, Metodología en el Turismo. México, Editorial Trillas, 1991.

Frederick F. ReICHELd e W. EARl SASSER, Zero Defections: Quality comes to Service. Harvard Business Review, September - October, 105-111, 1990.

Paul Ricoeur, Du texte à l'action. Paris, Seuil, 1986.

Doris Ruschmann, Marketing turístico: um enfoque promocional, São Paulo, Papirus.

Bernd H. SCHMitT, Experiential marketing: How to get customers to sense, feel, think, act and relate to your company and brands, New York, The Free Press, 1999.

BERND H. SCHMITT, Customer experience management: A revolutionary approach to connecting with your customers, New York, Wiley, 2003.

BERnd H. SCHMitT, Big think strategy: How to leverage bold ideas and leave small thinking behind, Boston, Harvard Business Press, 2007.

Bernd H. Schmitt, Experience Marketing: Concepts, Frameworks and Consumer Insights, Vol. 5, No. 2, páginas 55-112, 2010.

Bernd H. Schmitt, David L. Rogers, e Karen Vrotsos, There's no business that's not show business: Marketing in an experience culture. Englewood-Cliffs, NJ, Prentice-Hall Financial Times, 2003.

Bernd H. Schmitt, B., Lia Zarantonello e Kamel Jedidi, Functional and experiential routes to persuasion: An analysis of advertising in emerging versus developed markets, International Journal of Research in Marketing, 2013.

Richard Sharpley e Philipp R. Stone, Tourist Experience: Contemporary Perspectives, London, Routledge Advances in Tourism, 2011.

Gérard Tocquer e Michel Zins, Marketing do Turismo. Lisboa, Instituto Piaget, 1999.

JoHN URRY, The tourist gaze: leisure and travel in contemporary, London, Sague, 1993.

J acques A. Wainberg, Turismo e Comunicação: A Indústria da Diferença. São Paulo, Contexto, 2003. 